\title{
Laboratory Evaluation of Green Concrete Mixes Containing High Percentages of Steel Slag Coarse Aggregate
}

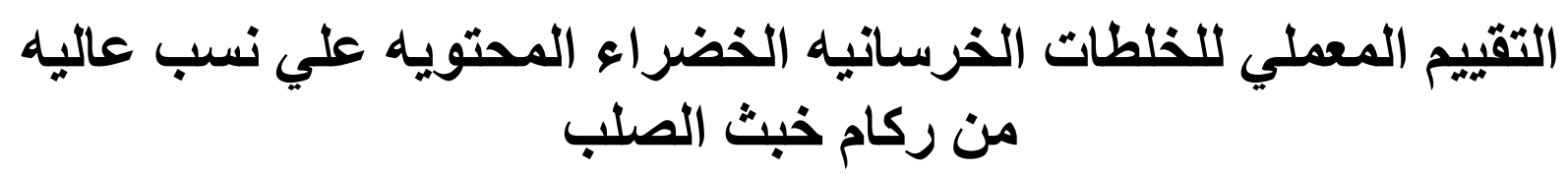

${ }^{4}$ Gamal M. Elgendy, ${ }^{1}$ Ali H. Elagamy, ${ }^{2}$ Mohamed A. Sherif, ${ }^{3}$ Sherif M. ELBadawy

${ }^{4}$ B.Sc. Civil Eng. Faculty of Engineering Mansoura University, Egypt. (E-mail: gymy216@yahoo.com)

${ }^{1}$ Associate Professor, Dept. of Structural Eng., Faculty of engineering, Mansoura University, Egypt, ${ }^{2}$ Assistant Professor, Depart. of Civil and Architectural

Constructions, Faculty of Industrial Education, Suez Univ., Egypt, ${ }^{3}$ Associate Professor, Public Works Dept., Faculty of engineering, Mansoura University, Egypt, E-mail: sbadawy@mans.edu.eg

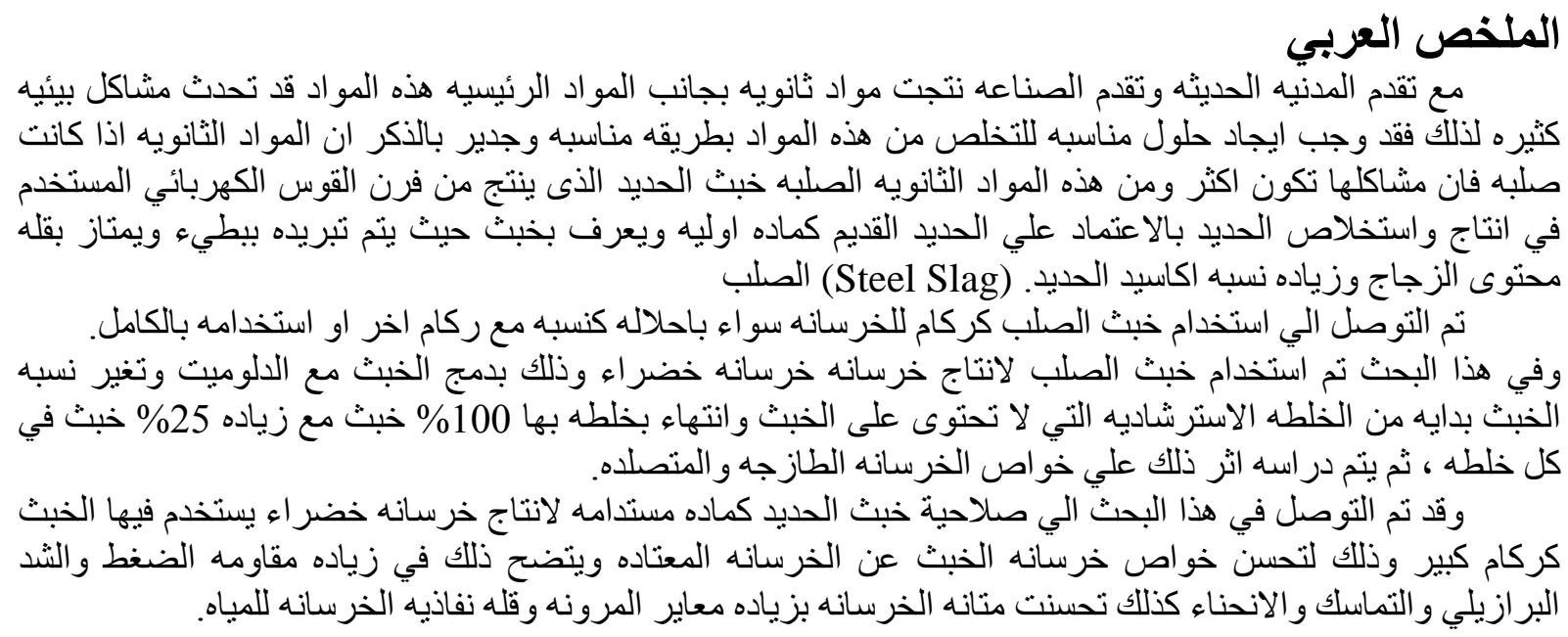

\section{Abstract}

Sustainability in the built environment is of increasing importance, particularly in the concrete structures. Slag from iron and steel industries can be used in some cases to replace natural aggregates in construction. Steel slag aggregate is an engineered product with great potential as replacement to naturally occurring aggregates in construction projects due to its distinctive physical and chemical properties. It is a $100 \%$ recyclable material. In this research, a comprehensive laboratory evaluation of the use of steel slag as a Portland Cement Concrete (PCC) aggregate was conducted. The performance of steel slag aggregates as a construction material in comparison to dolomite aggregates was evaluated. PCC mixtures with 0/100, 25/75, 50/50, 75/25, 100/0 percentages of steel slag/dolomite aggregates were prepared in the laboratory. All parameters in the mixes were kept constant except the coarse aggregate proportions. Test results revealed that steel slag has great potential as a construction material. The resulted concrete with steel slag showed relatively high compressive, splitting, flexural and bond strength as well as higher modulus of elasticity and lower permeability. Finally, the optimum amount of steel slag replacement was found to be $50 \%$ of the coarse aggregate.

\section{Key words}

Steel slag; Dolomite; Mechanical properties; Modulus of elasticity; Permeability; Green Concrete. 


\section{1-Introduction}

As the country's population and industries grow, enormous quantities of waste materials are generated every year in Egypt. Many of these waste materials are non-decaying elements and will remain in the environment for hundreds and perhaps thousands of years.

This situation combined with the ever increasing consumer population and demand, has resulted in a waste disposal crisis. The facts about reduced cost on extracting and processing a new raw material and consumption of virgin materials through reusing these materials are stated in various studies since the past decades. Recycling these waste materials innovatively and effectively into concrete construction materials can address concerns about the vast quantities of useful materials being discarded and wasted [1]. One of these waste materials which could be made into good use for construction needs is steel slag.

Utilization of steel slag as construction aggregate may reduce the cost of extracting and processing naturally occurring aggregates. The steel producing industry may also reduce their cost for treating and disposing the vast number of steel slag stockpiles. On its impact at preserving the environment, utilization of steel slag aggregate in various ways may directly reduce both the dependent on naturally occurring aggregate and the number of raw material-extracting projects [2].

The successful incorporation of steel slag as an aggregate in concrete has been studied in the past. Steel slag is an industrial by-product and instead of disposing it in the landfill, the use of such product in the construction market would increase efficiency and economy. The physical and chemical characteristics of steel slag have been carefully examined in this research. Due to its potentially expansive properties, it require special care if used in construction or other specific applications.
Sustainability in the built environment and producing green concrete are subjects of attraction, as natural aggregate supplies are depleted, pressures to use alternative materials such as steel slag increases. Steel slag is a by-product obtained either from conversion of iron to steel in a Basic Oxygen Furnace (BOF), or by the melting of scrap to make steel in the Electric Arc Furnace (EAF) [3]. The molten liquid is a complex solution of silicates and oxides that solidifies on cooling and forms steel slag. Steel slag is defined by the American Society for Testing and Materials (ASTM) as [a non-metallic product, consisting essentially of calcium silicates and ferrites combined with fused oxides of iron, aluminum, manganese, calcium and magnesium that are developed simultaneously with steel in basic oxygen, electric arc, or open hearth furnaces] [4]. The main constituents of iron and steel slag are silica, alumina, calcium, and magnesia, which together make about $95 \%$ of the total composition. [5]. The use of steel slag as an aggregate for (PCC) was laboratory researched in many countries, Much of this work has shown that properly aged steel slag can be non-expansive when used in PCC [6].

\section{2- Objectives}

The main objective of this research is to evaluate the properties of PCC mixtures containing different percentages of steel slag as a replacement of the course aggregate. In addition, this study also investigates the performance of steel slag aggregates as a construction material in comparison to dolomite aggregates and find out the optimum ratio of steel slag in PCC.

\section{3-Materials and Experimental Work}

The program is based on a controlling mix containing dolomite only as a coarse aggregate (M0), and then incorporate steel slag with dolomite beginning $25 \%$ steel slag with $75 \%$ dolomite (M1), $50 \%$ steel slag with $50 \%$ dolomite (M2), $75 \%$ steel 
slag with $25 \%$ dolomite (M3), and final $100 \%$ steel slag with $0 \%$ dolomite (M4), by weight from the total amount of coarse aggregate.

PCC mixtures with 0/100 (M0), 25/75 (M1), 50/50 (M2), 75/25 (M3), 100/0 (M4) percentages of steel slag/dolomite aggregates were prepared in the laboratory. The control mix (M0) contains no steel slag and all coarse aggregate in this mixture is dolomite aggregate.

All components in the mixes were kept constant except the coarse aggregate proportions which were changed as prescribed.

Fresh concrete properties were attained by means of slump test according to (ASTM C 143)

Hardened concrete properties were also attained according to specifications. The following tests were performed on the hardened concrete:

1. Compressive Strength of cubical Specimens following ASTM C 192 or BS 1881: part 116:1983

2. 2-Compressive Strength of Cylindrical Specimens following ASTM C 39

3. 3-Splitting Tensile Strength of Cylindrical Specimens following ASTM C 496

4. 4-Bond strength of a steel bar fixed in cylindrical concrete specimens.

5. 5-Flexural Strength of beam specimens following ASTM C 78 or BS 1881: part 118:1983

6. 6-Modulus of elasticity for Cylindrical Specimens following ASTM C469-65 (1975).

7. 7-Coefficient of permeability for cubical Specimens following.

In order to consider the effect of utilizing steel slag aggregate in concrete on compressive, splitting tensile, flexural and bond strengths, also modulus of elasticity and permeability coefficient, cube Samples of $15 \mathrm{~cm}$ side length, cylinders $\phi 15^{*} 30 \mathrm{~cm}$ and beams $10 * 10 * 50 \mathrm{Cm}$ were used.

A total number of five mixes were prepared and investigated; the properties of the investigated mixtures are illustrated in Table (1). The mix proportion per one cubic meter is shown in Table (2).

Table (1): Experimental Program

\begin{tabular}{|c|c|c|c|c|c|}
\hline \multirow{3}{*}{ 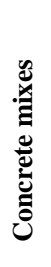 } & \multirow{3}{*}{ ن } & \multicolumn{3}{|c|}{ Aggregates \% } & \multirow{3}{*}{ 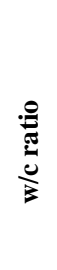 } \\
\hline & & \multirow[b]{2}{*}{ Fine } & \multicolumn{2}{|c|}{ Coarse } & \\
\hline & & & 䒿 & 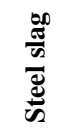 & \\
\hline M0 & 400 & $40 \%$ & $60 \%$ & $0 \%$ & 0.55 \\
\hline M1 & 400 & $40 \%$ & $45 \%$ & $15 \%$ & 0.55 \\
\hline M2 & 400 & $40 \%$ & $30 \%$ & $30 \%$ & 0.55 \\
\hline M3 & 400 & $40 \%$ & $15 \%$ & $45 \%$ & 0.55 \\
\hline M4 & 400 & $40 \%$ & $0 \%$ & $60 \%$ & 0.55 \\
\hline
\end{tabular}

Table (2): Mix Proportion " $k g / \mathrm{m}^{3 /}$

\begin{tabular}{|c|c|c|c|c|c|}
\hline \multirow{3}{*}{ 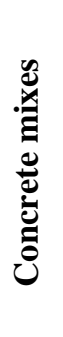 } & \multirow{3}{*}{ 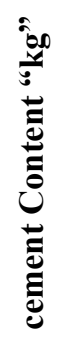 } & \multicolumn{3}{|c|}{ Aggregates "kg" } & \multirow{3}{*}{ 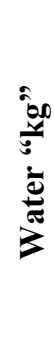 } \\
\hline & & \multirow[b]{2}{*}{ Fine } & \multicolumn{2}{|c|}{ Coarse } & \\
\hline & & & 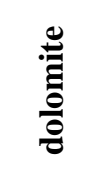 & $\frac{\vec{\sigma}}{\tilde{\sigma}}$ & \\
\hline M0 & 400 & 703.95 & 1055.9 & $\mathbf{0}$ & 220 \\
\hline M1 & 400 & 727.97 & 818.9 & 273 & 220 \\
\hline M2 & 400 & 753.68 & 565.2 & 565.3 & 220 \\
\hline M3 & 400 & 781.28 & 292.9 & 878.9 & 220 \\
\hline M4 & 400 & 810.98 & $\mathbf{0}$ & 1216.4 & 220 \\
\hline
\end{tabular}

Table (3): Chemical Analysis of EAFSS Aggregate

\begin{tabular}{|c|c|}
\hline Constituent & Composition \\
\hline SiO2 & 13.10 \\
\hline FexOy & 36.80 \\
\hline Al2O3 & 5.51 \\
\hline CaO & 33.0 \\
\hline MgO & 5.03 \\
\hline MnO & 4.18 \\
\hline Cr2O3 & 0.77 \\
\hline P2O5 & 0.74 \\
\hline TiO2 & 0.60 \\
\hline V2O5 & 0.10 \\
\hline SO3 & 0.14 \\
\hline
\end{tabular}

The steel slag used in this research was recruited from the Suez Steel Factory. This slag is denoted as EAFSS i.e. electric arc furnace steel slag. The EAFSS formed 
as a by-product during melting of scrap (the remains of used steel) from the impurities and fluxing agents, this form the liquid slag floating over the liquid crude iron or steel in electric arc furnace. The chemical analysis of the used EAFSS, as the manufacture provided, is shown in Table (3).

The EAFSS was manually crushed to sizes nearly similar to the sizes of the used dolomite stone by using crusher and sieves.

Siliceous sand is used as a fine aggregate with a percentage of $40 \%$ by weight of total aggregate. The coarse aggregate used is natural dolomite stone and is partially replaced by steel slag aggregate in $25 \%$ increments until all the natural aggregate were replaced by steel slag aggregate. The percent of water absorption, saturated surface dry (SSD) specific weight, percentage of clay and Bulk density for fine and coarse aggregates (dolomite and slag) were determined in the laboratory. The results are shown in Table (4). The gradation of the fine and coarse aggregate is given in Table (5).

The cement used in this research was supplied from Alarish Cement Company. This cement is ordinary Portland cement (OPC) type I and 52.5 grade as classified by ASTM C150.

Table (4): Properties of Aggregates

\begin{tabular}{|c|c|c|c|}
\hline & Sand & Dolomite & EAFSS \\
\hline $\begin{array}{c}\text { Water } \\
\text { Absorption\% }\end{array}$ & $1.2 \%$ & $3.0 \%$ & $8.0 \%$ \\
\hline $\begin{array}{c}\text { SSD specific } \\
\text { weight }\end{array}$ & 2.67 & $2.71 \%$ & $3.18 \%$ \\
\hline Clay \% & 0.60 & $\ldots--$ & $\ldots$ \\
\hline Bulk Density & 1664 & 1430 & 1885 \\
\hline
\end{tabular}

Table (5): Gradation of the fine and coarse aggregates

\begin{tabular}{|c|c|c|c|}
\hline \multirow{2}{*}{$\begin{array}{l}\text { Sieve Size } \\
\text { mm }\end{array}$} & \multicolumn{3}{|c|}{ Passing \% } \\
\hline & Sand & Dolomite & EAFSS \\
\hline 38 & 100 & 100 & 100 \\
\hline 25 & 100 & 100 & 100 \\
\hline 19 & 100 & 100 & 100 \\
\hline 12.5 & 100 & 98 & 97 \\
\hline 9.5 & 100 & 73 & 28 \\
\hline 4.75 & 95 & 0 & 0 \\
\hline 2.36 & 87.5 & 0 & $\mathbf{0}$ \\
\hline 1.18 & 72.5 & 0 & 0 \\
\hline 0.60 & 45 & 0 & $\mathbf{0}$ \\
\hline 0.30 & 10 & 0 & $\mathbf{0}$ \\
\hline 0.15 & $\mathbf{0}$ & 0 & 0 \\
\hline
\end{tabular}

\section{4-Results and Discussions 4-1 General:}

The effect of different parameters on the properties of concrete mixes in both fresh and hardened states is discussed. The mechanical properties as well as the main characteristics are presented to show the enhancement due to the presence of the steel slag aggregates. The results of compressive strength, splitting tensile strength, bond strength, and flexural strength are summarized in Table (6). Modulus of elasticity and coefficient of permeability results are shown in Table (7).

\section{4-2 Fresh Concrete Properties} 4-2-1 Consistency (Slump Test)

In general the use of slag without admixtures reduced the consistency of concrete. The reason is due to the surface texture, shape, porosity and the heavy specific weight of the steel slag aggregates. Table (6) shows the slump values of the investigated mixes. Figure (1) shows the 
relationship between the slump values of concrete and the replacement percentage of EAFSS aggregate for mixes with $400 \mathrm{~kg} / \mathrm{m}^{3}$ cement content. These mixes without admixtures lacked mobility and hence resulted in low slump values.

Table (6): Summary of Testing Results

\begin{tabular}{|c|c|c|c|c|c|c|c|c|c|c|}
\hline \multirow{2}{*}{ 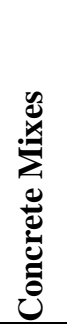 } & \multirow{2}{*}{$\begin{array}{l}\tilde{U} \\
\hat{\hat{\varepsilon}} \\
\hat{\bar{E}}\end{array}$} & \multicolumn{4}{|c|}{$\begin{array}{l}\text { Compressive Strength MPa } \\
\text { Cube } 15 * 15 * 15\end{array}$} & \multirow{2}{*}{ 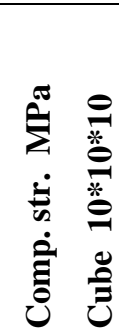 } & \multirow{2}{*}{ 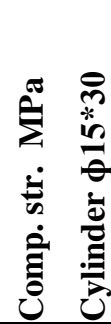 } & \multirow{2}{*}{ 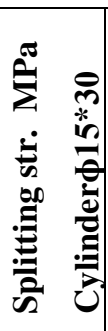 } & \multirow{2}{*}{ 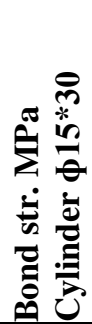 } & \multirow{2}{*}{ 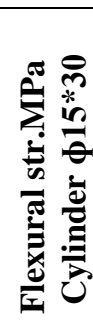 } \\
\hline & & $\underset{\sigma}{\sigma}$ & $\sum_{\infty}^{\infty}$ & $\hat{\sigma}_{0}^{0}$ & $\hat{e}_{0}^{\infty}$ & & & & & \\
\hline M0 & 14.0 & $\mathbf{3 0 . 1 7}$ & 37.62 & 43.62 & 46.01 & 39.24 & 25.62 & 2.60 & 5.94 & 5.53 \\
\hline M1 & 12.0 & 30.68 & 37.95 & 44.16 & 46.67 & 38.90 & 26.94 & 2.85 & 6.19 & 5.88 \\
\hline M2 & 11.0 & $\mathbf{3 4 . 3 5}$ & 41.86 & 46.42 & 49.72 & 43.20 & 28.88 & 3.22 & 6.95 & 6.66 \\
\hline M3 & 10.0 & 32.04 & 38.82 & 45.14 & 48.41 & 40.06 & 27.95 & $\mathbf{3 . 0 7}$ & 6.56 & 6.13 \\
\hline M4 & $\begin{array}{l}9.0 \\
\end{array}$ & 30.09 & $\mathbf{3 7 . 2 7}$ & 43.18 & 44.80 & 38.13 & 25.72 & $\mathbf{3 . 0 2}$ & 5.67 & 5.52 \\
\hline
\end{tabular}

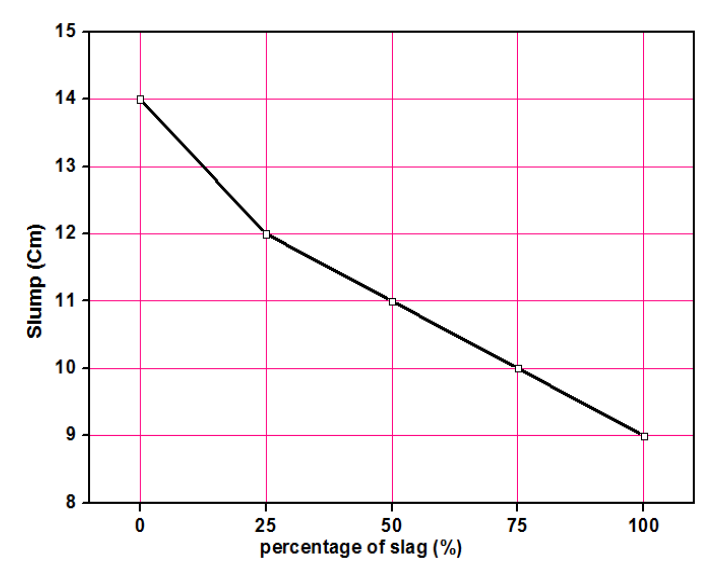

Fig. (1): Effect Of replacement Percentage of steel slag coarse aggregate on slump

\section{4-2-2 Fresh Density}

The unit weight of the fresh concrete was determined for the concrete cubes just after pouring and compaction. This value was the difference between the empty and filled cube. The laboratory estimated values for the fresh unit weight for M0, M1, M2, M3, and M4 were 2.49, 2.52, 2.64, 2.74, and $2.77 \mathrm{t} / \mathrm{m}^{3}$ respectively. Each value of the listed unit weight values is the average of twelve values (three cubes for each one age). It can be noticed that the unit weight of the normal steel slag aggregate concrete varied from $2.52 \mathrm{t} / \mathrm{m}^{3}$ to $2.77 \mathrm{t} / \mathrm{m}^{3}$. For the mix without steel slag aggregate (M0) the unit weight was $2.49 \mathrm{t} / \mathrm{m}^{3}$.

The mix unit weight was found to increase by about $11.24 \%$ from M0 to M4 mixes. The higher unit weight of the steel slag coarse aggregate concrete is attributed to the higher specific gravity of the used EAF steel slag aggregate. Table (8) shows the unit weight values of mixes, Figure (2) shows the relationship between the unit weight values of concrete and the replacement percentage of EAFSS aggregate for mixes.

Table (8): unit weight of the fresh concrete

\begin{tabular}{|c|c|}
\hline Concrete Mixes & Unit Weight t/m3 \\
\hline M0 & 2.49 \\
\hline M1 & 2.52 \\
\hline M2 & 2.64 \\
\hline M3 & 2.74 \\
\hline M4 & 2.77 \\
\hline
\end{tabular}




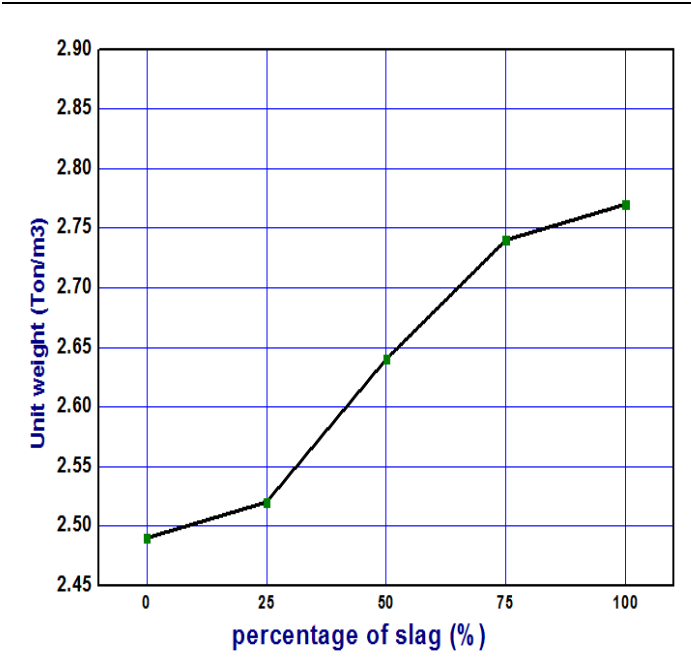

Fig. (2): Effect of Replacement Percentage of Steel Slag Coarse Aggregate on Unit Weight.

\section{4-3 Hardened Concrete Properties}

This part of study explains some properties of Hardened concrete containing steel slag as coarse aggregate partially or fully replacing traditional dolomite aggregate.

\section{4-3-1 Compressive Strength}

The incorporation of steel slag aggregate with traditional dolomite aggregate is expected to increase the compressive strength of the resulted concrete. The aim of this research is to find out the optimum percentage of steel slag aggregate to be replaced with dolomite aggregate to give maximum compressive strength relative to the controlling mix. Compressive strength results are listed in Table (6).

Fig (3) shows a comparison between the results of mixes M0, M1, M2, M3 and M4 at different ages. It can be observed that the concrete mix M2 which possessed replacement ratio of $50 \%$ recorded the highest compressive strength at all ages (7, 28, 56 and 90 days).

The increase in the compressive strength, especially in mixes with $50 \%$ steel slag coarse aggregate can be attributed to the better mechanical properties of the used steel slag as well as the high angularity of the steel slag which led to increase in the bond between the aggregate and cement paste.

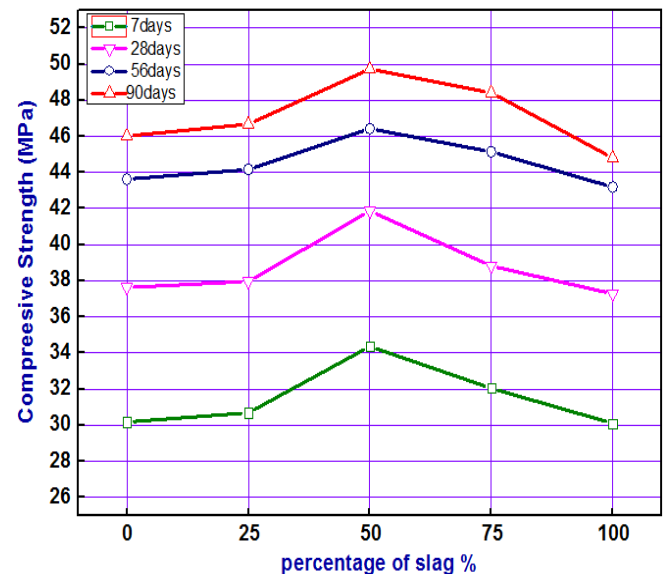

Fig. (3): Effect of Replacement Percentage of Steel Slag Coarse Aggregate on Compressive Strength for Different Ages.

\section{4-3-2 Splitting Tensile Strength}

The splitting or Brazilian tension test was conducted on cylindrical specimens' $\$ 15 \times 30 \mathrm{~cm}$ which were horizontally crushed after 28 days. The indirect tensile strength results are summarized in Table (6).

The effect of EAF replacement on the indirect tensile strength at the age of 28 days of the investigated mixes was studied.

.It can be observed that the concrete mix M2, which possessed replacement ratio of $50 \%$, yielded the highest splitting tensile strength after 28 days.

The increase in the indirect tensile strength can be attributed to the rough surface and high angularity of the steel slag which led to increase the bond between the aggregate and the cement past. Fig (4) shows the effect of replacement percentage of steel slag coarse aggregate on the indirect tensile strength at the age of 28 days. 


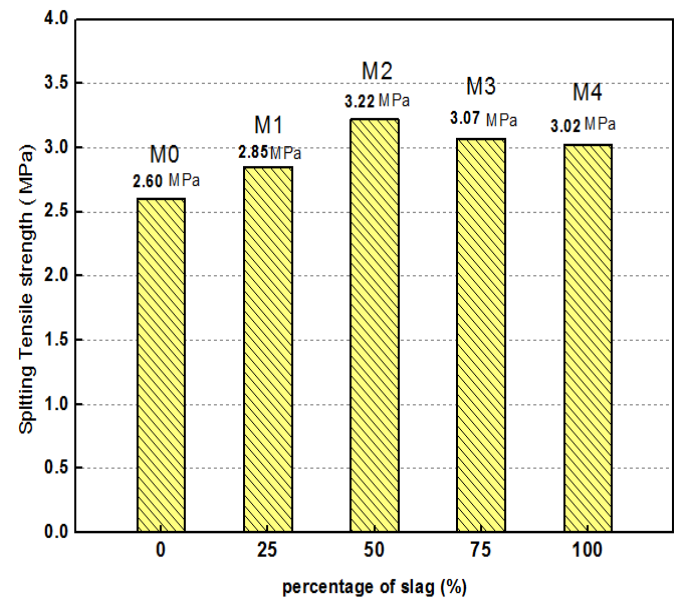

Fig. (4): Effect of Replacement Percentage of Steel Slag Coarse Aggregate on Splitting Tensile Strength at 28 Days.

\section{4-3-3 Bond Strength}

The bond test was conducted after 28 days on cylindrical specimens with $\phi 16$ steel bar fixed in its centerline which was pulled out until slipping or cutting. Bond strength for the investigated mixes is shown in Table (6).

It can be also observed that the concrete mix M2 showed the highest bond strength after 28 days. This is shown in Fig (5).

The increase in the bond strength can be attributed to the rough surface and high angularity of the steel slag which led to increase the bond between the aggregate and the cement past.

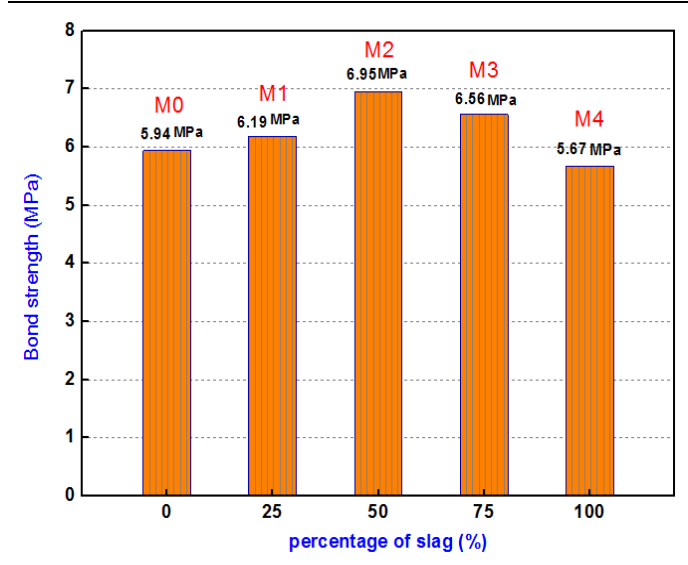

Fig. (5): Effect of Replacement Percentage of Steel Slag Coarse Aggregate on Bond Strength at 28 Days.

\section{4-3-4 Flexural Strength}

The flexural or bending test was conducted after 28 days on prismatic specimens with effective length of $45 \mathrm{~cm}$ and third points loading. The loads were applied until failure occurred. The flexural or bending strength results for the investigated mixes are listed in Table (6). Fig (6) shows the effect of replacement percentage of steel slag coarse aggregate on the flexural strength at age of 28 days. It also shows that among the investigated mixes, the mix M2 had the highest flexural strength.

The increase in the flexural strength as the percentage of slag increased can be attributed to the rough surface and high angularity of the steel slag.

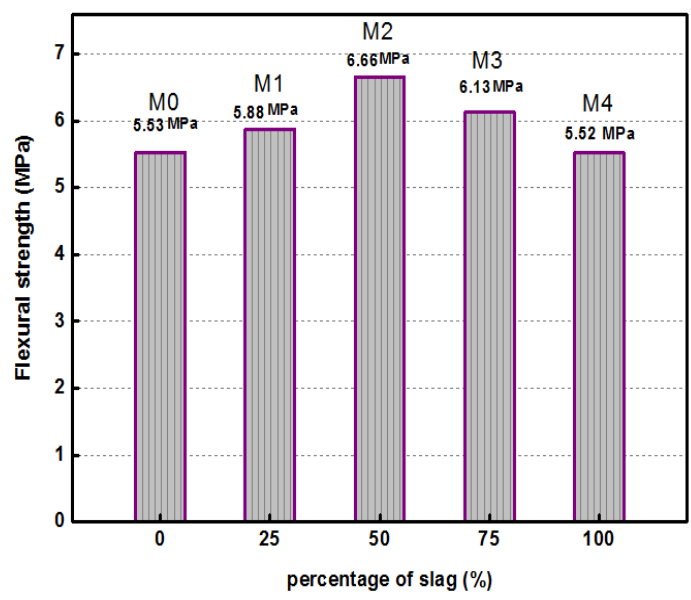

Fig.(6): Effect of Replacement Percentage of Steel Slag Coarse Aggregate on Flexural Strength at 28 days.

\section{4-4 Modulus of Elasticity}

The test for estimating of the static modulus of elasticity was done on cylindrical specimens after 28 days. The specimens were vertically loaded and unloaded for three cycles. The static modulus of elasticity is the slope of the last loading cycle. The modules of elasticity testing results are summarized in Table (7).

The increase in the modulus of elasticity can be attributed to the rough surface and high angularity of the steel slag which led to increase the bond between the aggregate and the cement past. Fig (7) shows the effect of replacement percentage 
of steel slag coarse aggregate on the modulus of elasticity at 28 days age. The figure shows that the mix M2 has the highest modulus of elasticity.

Table (7): Coefficient of Permeability and Modulus of Elasticity at 28 days Age

\begin{tabular}{|c|c|c|}
\hline 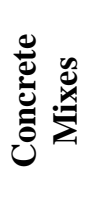 & 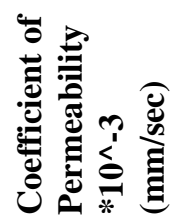 & 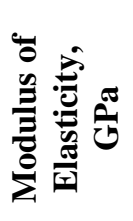 \\
\hline M0 & 3.5 & 28.47 \\
\hline M1 & 3 & 28.58 \\
\hline M2 & 2.7 & 29.82 \\
\hline M3 & 2.9 & 28.86 \\
\hline M4 & 3 & 28.36 \\
\hline
\end{tabular}

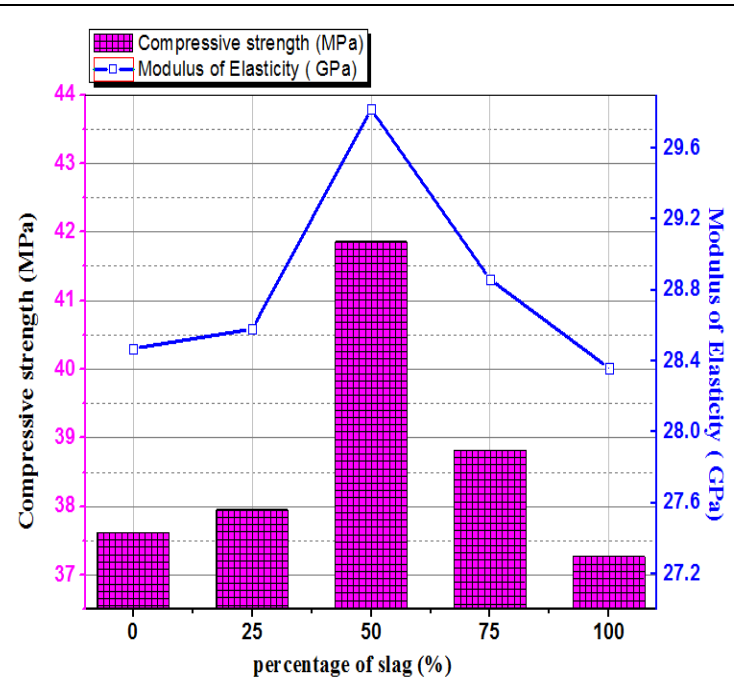

Fig. (7): Effect of replacement Percentage of steel slag coarse aggregate on Modulus of Elasticity

\section{4-5 Water Permeability}

The water permeability coefficient in $\mathrm{mm} / \mathrm{sec}$ was measured by means of the German water permeability apparatus (GWP). The values of the permeability coefficient of the five investigated concrete mixes are listed in Table (7).

Figure (8) illustrates the effect of the percentage of replacement of steel slag coarse aggregate on the permeability coefficient. As shown in this figure, in general, increasing the replacement percentage of the used steel slag coarse aggregate decreased the permeability of the concrete. This can be attributed to the better physical and mechanical properties of the steel slag coarse aggregate if compared with the used natural coarse aggregate. The figure also shows that M2 mix has the lowest coefficient of permeability. This finding agrees quit well with the results of this study.

It's worth mentioning that decreasing the permeability coefficient improves the durability of concrete

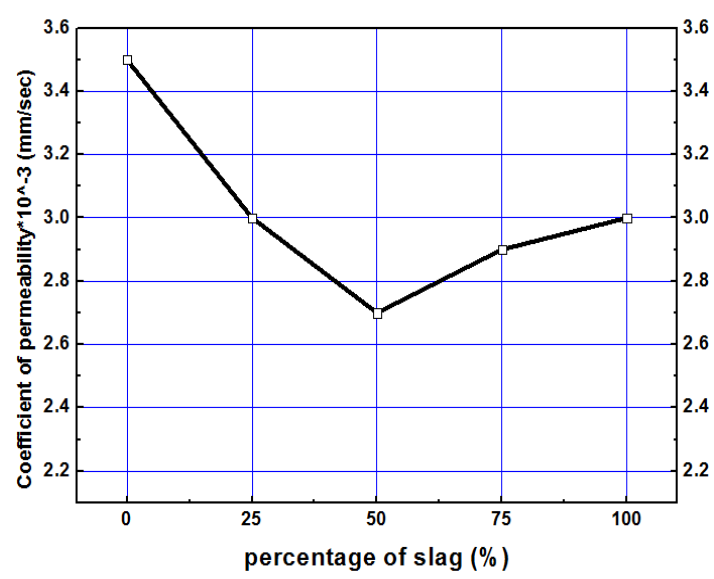

Fig. (8): Effect of Replacement Percentage of Steel Slag Coarse Aggregate on Coefficient of permeability

\section{5-Conclusions}

Based on the results of this research, the following conclusions were found:

1) The use of slag without admixtures reduced the consistency of concrete due to the surface texture, shape, porosity and the heavy specific weight of the steel slag aggregates.

2) An increase of about $11.24 \%$ in the unit weight for the steel slag coarse aggregate concrete occurred.

3) The replacement of 50\% (by weight) of the natural coarse aggregate by steel slag enhanced the compressive strength, indirect tensile strength, bond strength, flexural strength, and modulus of elasticity. At this percentage, the resulted coefficient of permeability of concrete was the lowest. 


\section{References}

[1.] Mahmud Ameri, Hossein Shahabishahmiri, Sanaz

Kazemzadehazad, "Evaluation of the Use Of Steel Slag In Concrete". 25th ARRB Conference - Shaping the future: Linking policy, research and outcomes, Perth, Australia (2012)

[2.] Teoh Cherh Yi "Performance Evaluation of Steel Slag as Natural Aggregates Replacement in Asphaltic Concrete" Thesis submitted as fulfillment of the requirements For the degree of Master of Science (November 2008).

[3.] Asmaa M. N. abdel Hamid, "Behavior of concrete containing local steel slag as coarse Aggregate", A Thesis submitted to the faculty of industrial education- suez university, Egypt, (2014).

[4.] Jigar P. Patel, "Broder Use of steel Slag Aggregates in Concrete" MSc Thesis, The Cleveland State University (December 2008).

[5.] National Slag Association MF 182-6 "Properties and Uses of Iron and Steel Slag".

[6.] Brad Fronek, Paul Bosela, Norbert Delatte, "US and International Prespectives on The Use of Steel Slag Aggregate in Portland Cement", TRB Annual Meeting Paper revised from original submittal (2012).

[7.] Han Young Moon, Jung Hoon Yoo and Seong Soo Kim, "A Fundamental Study on the Steel Slag Aggregate for Concrete" Geosystem Eng., 5(2), 3845, (June 2002).

[8.] Tahir Sofilić, Ana Mladenovič, Una Sofilić, "Characterization of the Eaf Steel Slag as Aggregate for Use in Road Construction "Corresponding author: tahir.sofilic@cmc.com.

[9.] I. Netinger, M. Jelčić Rukavina \& D. Bjegović A. Mladenovič, "Concrete containing steel slag aggregate: Performance after high Temperature exposure" Concrete Repair, Rehabilitation and Retrofi tting III -
Alexander et al. (eds) (2012) Taylor \& Francis Group, London, ISBN 9780-415-89952-9.

[10.] Mladen Fistri, Andrea Strineka, Ružica Roskovic," Properties of steel slag aggregate and steel slag asphalt concrete" 10. Slovenski Kongres O Cestah in Prometu, Portorož, 20. - 22. (October) 2010.

[11.] Mohd Rosli Hainin, Nur IzziMd. Yusoff," Steel Slag as an Aggregate Replacement In Malaysian HotMix Asphalt" International Scholarly Research Network ISRN Civil Engineering Volume 2012, Article ID 459016, 5 pages doi:10.5402/2012/459016.

[12.] Han Ay Lie and Moga Narayudha "Steel-Slag as Aggregate Substitute's Influence to Concrete's Shear Capacity" An Experimental Approach.

[13.] Abbass Salim Abbass AL-Ameeri Suhaila Gh. Mattar, "The Use of Local Slag as Coarse Aggregate in concrete"

[14.] R. Alizadeh, M. Chini, P. Ghods, M. Hoseini, Sh. Montazer, M. Shekarchi "Utilization of Electric Arc Furnace Slag as Aggregates in Concrete -Environmental Issue" 6th Canmet/ACI International Conference on Recent Advances in Concrete Technology, Bucharest, Romania, pp. 451-464, (June 2003).

[15.] John Emery, Vp, Trow Ltd. Consulting Engineers, "Steel Slag Utilization In Asphalt Mixes " Taken from Canadian Technical Asphalt Association Proceedings, (1984).

[16.] Liz Hunt, and Glenn E. Boyle, "Steel Slag in Hot Mix Asphalt Concrete" Research Group Oregon Department of Transportation, Salem, Oregon 97301-5192 (April 2000). 